\title{
LIFETIME PREDICTION FOR MODEL 9975 O-RINGS IN KAMS
}

\author{
E. N. Hoffman and T.E. Skidmore \\ SAVANNAH RIVER NATIONAL LABORATORY \\ Materials Science \& Technology
}

November 2009

Savannah River Nuclear Solutions

Savannah River Site

Aiken, SC 29808

This document was prepared in conjunction with work accomplished under

Contract No. DE-AC09-08SR22470 with the U.S. Department of Energy. 


\section{DISCLAIMER}

This work was prepared under an agreement with and funded by the U.S. Government. Neither the U. S. Government or its employees, nor any of its contractors, subcontractors or their employees, makes any express or implied: 1.warranty or assumes any legal liability for the accuracy, completeness, or for the use or results of such use of any information, product, or process disclosed; or 2. representation that such use or results of such use would not infringe privately owned rights; or 3 . endorsement or recommendation of any specifically identified commercial product, process, or service. Any views and opinions of authors expressed in this work do not necessarily state or reflect those of the United States Government, or its contractors, or subcontractors. 


\section{TITLE: LIFETIME PREDICTION FOR MODEL 9975 O-RINGS IN KAMS (U)}

\section{APPROVALS}

E.N. Hoffman, Author

Date:

SRNL/MATERIALS SCIENCE \& TECHNOLOGY

T.E. Skidmore, Author

Date:

SRNL/MATERIALS SCIENCE \& TECHNOLOGY

W.L. Daugherty, Technical Reviewer

Date:

SRNL/MATERIALS SCIENCE \& TECHNOLOGY

K.A. Dunn

Date:

SRNL Pu Surveillance Program Lead

SRNL/MATERIALS SCIENCE \& TECHNOLOGY

G.T. Chandler, Manager

Date:

SRNL/MATERIALS SCIENCE \& TECHNOLOGY

N.C. Iyer, Director,

Date:

SRNL/MATERIALS SCIENCE \& TECHNOLOGY

E.R. Hackney

Date:

NMM Engineering

Reviewed by: J. L. Murphy

Date:

SRNL/Packaging Technology 


\section{TABLE OF CONTENTS}

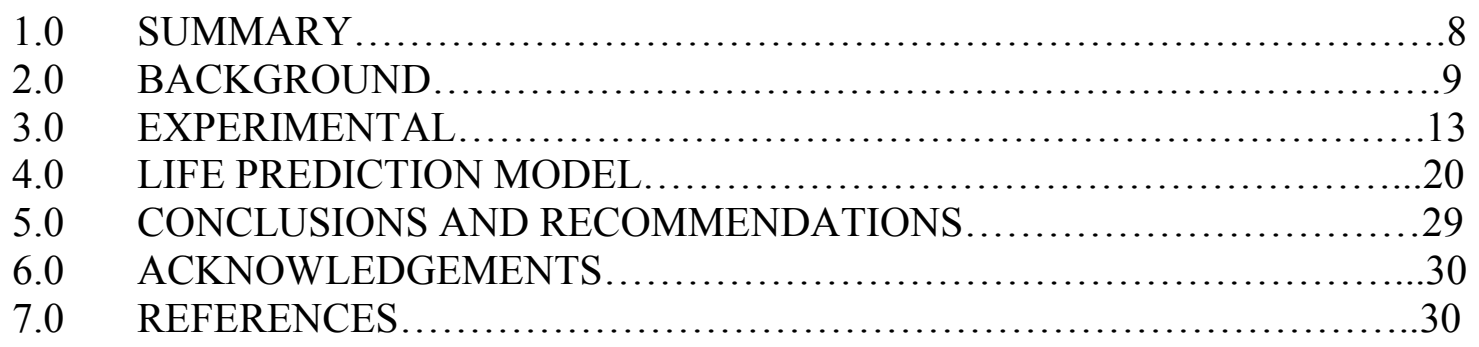




\section{LIST OF TABLES}

Table 1 Model 9975 O-ring ID stretch and \% compression values [10].........................11

Table 2 Testing matrix for compression stress relaxation testing. ................................. 17

Table 3 M-Scale hardness measurements for as-received Viton ${ }^{\circledR}$ GLT O-rings.............. 17

Table 4 Estimated time to failure at various temperatures based on the basic Arrhenius

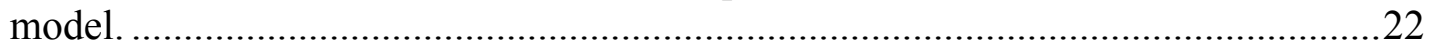




\section{LIST OF FIGURES}

Figure 1 Model 9975 containment vessel seal design [2] .............................................. 10

Figure 2 As-installed O-ring profile. ....................................................................... 12

Figure 3 Baseline CSR data for Parker V0835-75 O-rings (size 2-226) vs. temperature. 14

Figure 4 Wallace-Cogenix Mark IV Stress Relaxometer................................................15

Figure 5 C11 CSR jig with custom 9975 stretch insert. ...............................................16

Figure 6 CSR Behavior of V0835-75 O-rings aged at 175 to $350^{\circ} \mathrm{F}$................................19

Figure 7 Short-term baseline CSR aging model (time to target relaxation values vs.

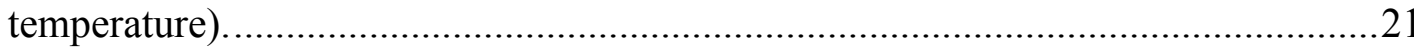

Figure 8 Time-Temperature Superposition curve for V0835-75 CSR data $\left(\mathrm{T}_{\text {ref }}=175^{\circ} \mathrm{F}\right) .24$

Figure 9 Plot of $\log \mathrm{a}_{\mathrm{T}}$ shift factors vs temperature. The activation energy derived from

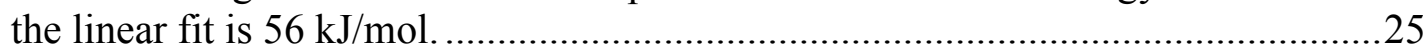

Figure 10 Estimated O-ring service life (based on CSR) vs seal temperature using $E_{a}$ of

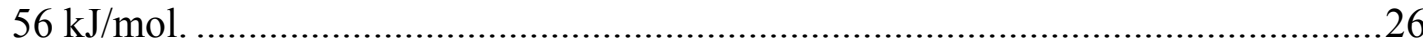




\section{LIST OF ACRONYMS, TRADENAMES, AND ABBREVIATIONS}

\begin{tabular}{|c|c|}
\hline AMS & Aerospace Material Specification \\
\hline ASTM & American Society for Testing and Materials \\
\hline CSR & compression stress-relaxation \\
\hline $\mathrm{CS}$ & compression set (also cross-section) \\
\hline DOE & Department of Energy \\
\hline DOT & Department of Transportation \\
\hline DSA & Documented Safety Analysis \\
\hline DLO & diffusion-limited oxidation \\
\hline DMA & dynamic mechanical analysis \\
\hline DSC & differential scanning calorimetry \\
\hline EPDM & ethylene-propylene diene monomer \\
\hline GLT & $\begin{array}{l}\text { peroxide-cured, low temperature fluoroelastomer (DuPont Performance } \\
\text { Elastomers) }\end{array}$ \\
\hline GLT-S & newer version of GLT (DuPont Performance Elastomers) \\
\hline Gray & international unit for radiation dose, $1 \mathrm{~Gy}=100 \mathrm{rad}$ \\
\hline HAC & Hypothetical Accident Conditions \\
\hline ID & inner diameter \\
\hline KAMS & K-Area Material Storage \\
\hline MS\&T & Materials Science \& Technology \\
\hline $\mathrm{NCT}$ & Normal Conditions of Transport \\
\hline PCV & primary containment vessel \\
\hline $\mathrm{R}$ & universal gas constant, $8.31 \mathrm{~J} / \mathrm{mol}-\mathrm{K}(1.987 \mathrm{cal} / \mathrm{mol}-\mathrm{K})$ \\
\hline RAM & Radioactive Material \\
\hline $\mathrm{rad}$ & radiation absorbed dose, equal to $100 \mathrm{ergs} / \mathrm{gram}$ \\
\hline SARP & Safety Analysis Report for a Package \\
\hline $\mathrm{SCV}$ & secondary containment vessel \\
\hline SNL & Sandia National Laboratory \\
\hline SRNL & Savannah River National Laboratory \\
\hline SRPT & Savannah River Packaging Technology \\
\hline SRS & Savannah River Site \\
\hline TTS & Time-temperature superposition \\
\hline Viton $^{\circledR}$ & tradename for DuPont Performance Elastomers fluoroelastomer \\
\hline
\end{tabular}




\subsection{SUMMARY}

The Savannah River Site (SRS) is currently storing plutonium materials in the K-Area Materials Storage (KAMS) facility. The materials are packaged per the DOE 3013 Standard and transported and stored in KAMS in Model 9975 shipping packages, which include double containment vessels sealed with dual O-rings made of Parker Seals compound V0835-75 (based on Viton ${ }^{\circledR}$ GLT). The outer O-ring of each containment vessel is credited for leaktight containment per ANSI N14.5.

O-ring service life depends on many factors, including the failure criterion, environmental conditions, overall design, fabrication quality and assembly practices. A preliminary life prediction model has been developed for the V0835-75 O-rings in KAMS. The conservative model is based primarily on long-term compression stress relaxation (CSR) experiments and Arrhenius accelerated-aging methodology. For model development purposes, seal lifetime is defined as a $90 \%$ loss of measurable sealing force. Thus far, CSR experiments have only reached this target level of degradation at temperatures $\geq 300^{\circ} \mathrm{F}$. At lower temperatures, relaxation values are more tolerable. Using time-temperature superposition principles, the conservative model predicts a service life of approximately 20-25 years at a constant seal temperature of $175^{\circ} \mathrm{F}$. This represents a maximum payload package at a constant ambient temperature of $104{ }^{\circ} \mathrm{F}$, the highest recorded in KAMS to date. This is considered a highly conservative value as such ambient temperatures are only reached on occasion and for short durations. The presence of fiberboard in the package minimizes the impact of such temperature swings, with many hours to several days required for seal temperatures to respond proportionately.

At $85{ }^{\circ} \mathrm{F}$ ambient, a more realistic but still conservative value, bounding seal temperatures are reduced to $\sim 158{ }^{\circ} \mathrm{F}$, with an estimated seal lifetime of $\sim 35-45$ years. The actual service life for O-rings in a maximum wattage package likely lies higher than the estimates due to the conservative assumptions used for the model. For lower heat loads at similar ambient temperatures, seal lifetime is further increased.

The preliminary model is based on several assumptions that require validation with additional experiments and longer exposures at more realistic conditions. The assumption of constant exposure at peak temperature is believed to be conservative. Cumulative damage at more realistic conditions will likely be less severe but is more difficult to assess based on available data. Arrhenius aging behavior is expected, but non-Arrhenius behavior is possible. Validation of Arrhenius behavior is ideally determined from longer tests at temperatures closer to actual service conditions. CSR experiments will therefore continue at lower temperatures to validate the model. Ultrasensitive oxygen consumption analysis has been shown to be useful in identifying non-Arrhenius behavior within reasonable test periods. Therefore, additional experiments are recommended and planned to validate the model. 


\subsection{BACKGROUND}

The Savannah River Site (SRS) is storing plutonium $(\mathrm{Pu})$ materials in the K-Area Materials Storage (KAMS) facility. The Pu materials are packaged per the DOE 3013 Standard which requires nested, welded stainless steel containers [1]. The welded 3013 containers are transported in DOT Type B shipping packages, specifically the Model 9975, to KAMS for storage [2]. The 9975 containment vessels are made of stainless steel and are sealed with a cone seal plug containing dual O-rings (Figure 1). The outer O-ring of each vessel is credited as being leaktight. The lower O-rings provide a leak test volume and a second containment barrier.

The O-ring compound historically specified in the Model 9975 SARP is Parker Seals V0835-75. The V0835 is a compound designation, with 75 being the compound hardness (75+/-5 Durometer A). This compound is based on Viton ${ }^{\circledR}$ GLT fluoroelastomer (DuPont Performance Elastomers). Viton ${ }^{\circledR}$ GLT is a terpolymer consisting of vinylidene fluoride (VF2), permethylvinyl ether (PMVE) and tetrafluoroethylene (TFE) monomers, with a proprietary cure site monomer (CSM) based on bromine. Viton ${ }^{\circledR}$ GLT was specifically developed to allow peroxide curing and low-temperature performance, due principally to the PMVE monomer [3]. The V0835-75 compound is used in many industries and is specified in several radioactive material packages, including the 9975 , due to its balance of properties.

The V0835-75 compound is generally rated for service at -40 to $400{ }^{\circ} \mathrm{F}$. Such temperature ranges as established by seal manufacturers are often interpreted as "continuous". However, such ranges are typically based on relatively short-term data (e.g. 1000 hours) as indicated in the Parker O-Ring Handbook [4]. Temperatures within the range should be tolerable for longer periods, but not necessarily forever. Higher temperatures may also be possible for short periods.

In KAMS, a peak PCV O-ring temperature of $202^{\circ} \mathrm{F}$ is possible for a $19 \mathrm{~W}$ payload $(0.8$ liter can/oxide) at $130^{\circ} \mathrm{F}$ ambient [5]. Assuming a linear correlation, the highest ambient temperature measured in KAMS to date $\left(104{ }^{\circ} \mathrm{F}\right)$ reduces the peak PCV O-ring temperature to $176^{\circ} \mathrm{F}$ [6]. Ambient temperatures in KAMS range from 55 to $85^{\circ} \mathrm{F}$, driving seal temperatures to $\sim 127-157^{\circ} \mathrm{F}$ for packages with maximum heat load. Lower ambient conditions or lower payloads further reduce seal temperatures.

The peak room temperature reached during loss of ventilation is $137^{\circ} \mathrm{F}$ at an ambient 86 ${ }^{\circ} \mathrm{F}$ [7]. If a linear correlation, the O-ring temperature is $\sim 209^{\circ} \mathrm{F}$. The duration of this scenario has not been defined.

The bounding radiation dose rate for the $9975 \mathrm{PCV}$ seals is $2 \mathrm{rad} / \mathrm{hr}$ [8] for an annual dose of $1.75 \mathrm{E}+04 \mathrm{rad}$, primarily from photon contributions. This is a mild dose rate relative to material degradation. A conventional limit of $10 \mathrm{Mrad}$ would be reached in $\sim 570$ years at this rate. Previous SRNL tests have shown that the O-rings can remain leaktight after a $100 \mathrm{Mrad}$ dose imposed at very high dose rates [9]. However, significant degradation could occur at lower doses with the lower dose rate experienced in these packages. 


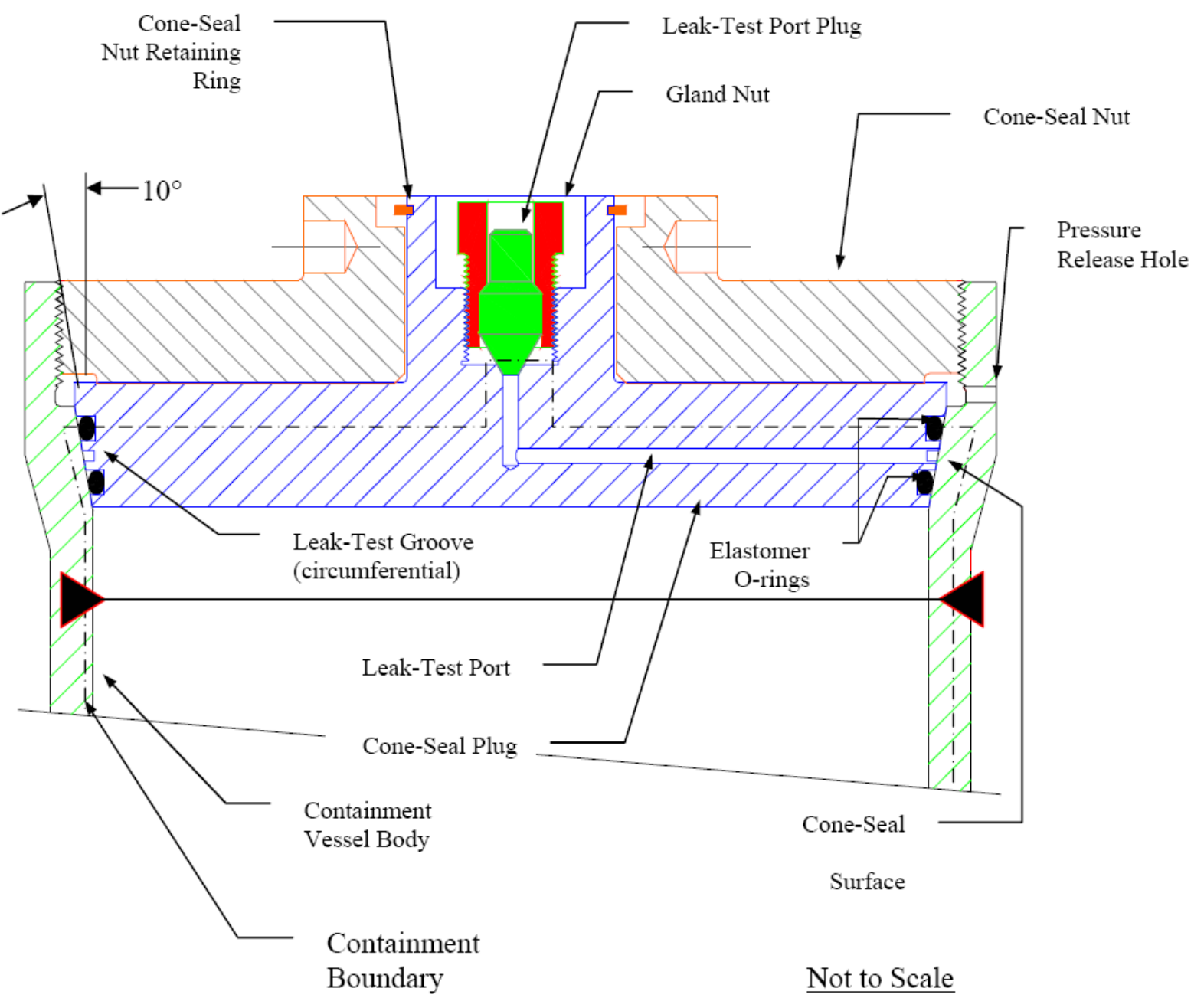

Figure 1 Model 9975 containment vessel seal design [2].

PCV and SCV O-ring sizes are Parker size 2-244 and 2-252, same as AS568A sizes -244 and -252. PCV O-rings have a thickness of $0.139+/-0.005$ " with a $4.234+/-0.045$ " ID. SCV O-rings have the same thickness but a larger ID (5.234+/-0.054").

Several O-ring design parameters are important for performance, particularly ID stretch, percent compression, gland fill and mating surface finish. The nominal O-ring compression values given in the 9975 SARP are $28 \%$ (zero gap) and $21 \%$ (0.01" gap) [2]. The 0.01 " gap is only used to calculate unseating pressures and is not a normal condition.

These values do not account for O-ring flattening and thinning due to ID stretch. Based on O-ring and part dimensions, Table 1 shows the nominal ID stretch is $18.7 \%$ and $15.9 \%$ for PCV and SCV outer O-rings [10]. These values are higher than normally recommended by O-ring manufacturers ( $5 \%$ max). 
Table 1 Model 9975 O-ring ID stretch and \% compression values [10].

\begin{tabular}{|c|c|c|c|}
\hline & $\begin{array}{c}\text { Percent Stretch } \\
\text { PCV } \\
\text { Outer/Inner } \\
(\%)\end{array}$ & $\begin{array}{c}\text { Percent Stretch } \\
\text { SCV } \\
\text { Outer/Inner } \\
(\%)\end{array}$ & $\begin{array}{c}\text { Percent } \\
\text { Compression } \\
\text { Outer } \\
\text { 0.00 Gap } / 0.01 \\
\text { Gap (\%) }\end{array}$ \\
\hline $\begin{array}{c}\text { Maximum } O \text {-ring } \\
\text { Stretch: Largest Cone } \\
\text { Seal Plug/Smallest O- } \\
\text { ring }\end{array}$ & $20.7 / 17.8$ & $17.7 / 15.3$ & $\begin{array}{c}\text { Primary: } \\
\text { 16.4/8.0 } \\
\text { Secondary: } \\
17.8 / 9.5\end{array}$ \\
\hline $\begin{array}{l}\text { Nominal Cone Seal } \\
\text { Plug/Nominal O-ring }\end{array}$ & $18.7 / 15.9$ & $15.9 / 13.7$ & $\begin{array}{l}\text { Primary: } \\
20.4 / 12.4 \\
\text { Secondary } \\
21.6 / 13.8\end{array}$ \\
\hline $\begin{array}{c}\text { Minimum O-ring } \\
\text { Stretch: Smallest Cone } \\
\text { Seal Plug/Largest O- } \\
\text { ring }\end{array}$ & $16.7 / 14.2$ & $14.1 / 12.0$ & $\begin{array}{l}\text { Primary: } \\
23.4 / 15.7 \\
\text { Secondary } \\
24.6 / 17.0\end{array}$ \\
\hline
\end{tabular}

The effect of higher ID stretch during shipping is believed to be negligible, but could be more significant during storage. The two general effects of ID stretch are: 1) reduced compression/gland fill and 2) tensile stress. The Parker O-Ring Handbook states that higher ID stretch is likely more acceptable for certain elastomers including Viton ${ }^{\circledR}$ fluoroelastomer than other types more sensitive to aging and oxidation such as nitrile rubber, but specific values are not provided.

The effect of ID stretch (thickness reduction and flattening) is shown in Figure 2. The nominal protrusion of the upper PCV O-ring above the O-ring groove is $\sim 0.0255$ " compared to $\sim 0.0395$ " for an unstretched O-ring $(\sim 10 \%$ reduction in effective thickness, from 0.139 " to 0.124 "). The nominal protrusion ( 0.0255 ") is approximately $20.6 \%$ of the stretched 0.124 " thickness, lower than the unstretched SARP value of $28 \%$, but still within the $16-23 \%$ range quoted by the manufacturer for sizes 2-201 to 2-284 [4]. The calculated values of reduced thickness from ID stretch are based on empirical formulas presented in the Parker O-Ring Handbook. 


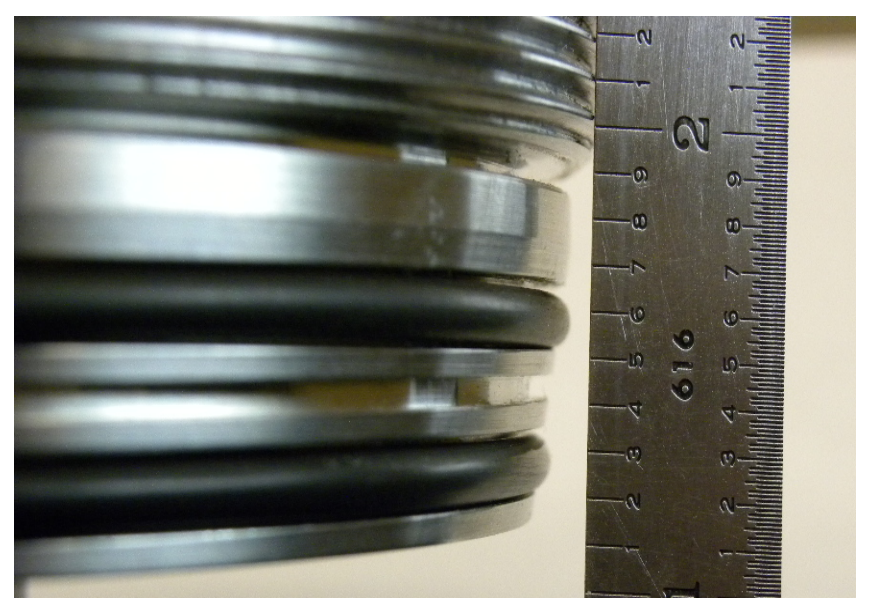

Figure 2 As-installed O-ring profile.

Per the Parker O-Ring Handbook, the recommended gland fill range is $60-85 \%$. The range is needed to account for tolerance stacking and possible thermal expansion. A $10 \%$ void is typically recommended for any sealing gland. Using nominal dimensions for the O-ring groove ( 0.113 " top, 0.086 " bottom, 0.152 " width), the average gland fill for a zero-gap design is estimated at $0.0151 \mathrm{in}^{2}$. Using the nominal diameter and the percentage stretch, O-ring thickness of a stretched PCV O-ring (0.124”) is calculated, leading to an average area of the O-ring cross-section of approximately $0.0123 \mathrm{in}^{2}$. Therefore, the percentage of average gland fill resulting from the ratio between the stretched PCV O-ring cross-section and the groove cross-section is approximately $81 \%$.

The surface finish requirement for the O-ring gland and mating surfaces is $32 \mu$-inches or 32 RMS. This is a standard surface finish normally considered acceptable for leaktight designs. A 16 RMS finish or better is recommended for gas seals. However, some minimum degree of roughness is usually needed to ensure capture of lubricant to aid in sealing.

\subsection{EXPERIMENTAL}

\subsection{Test Methodology}

Though a very robust shipping package, the Model 9975 was not specifically designed for long-term material storage. Therefore, a surveillance program was initiated to monitor the performance of the O-rings and Celotex ${ }^{\circledR}$ fiberboard insulation materials over time during storage in KAMS. For O-rings, this program has involved three main aspects: 1) field and laboratory examination of storage-aged O-rings, 2) periodic leak testing of PCV fixtures aged at bounding conditions and 3) CSR testing following accelerated-aging. This report will discuss the compression stress relaxation testing and the subsequent lifetime prediction based on time-temperature-superposition evaluation of the experimental data. 
In 2006, DuPont announced that the GLT polymer was being replaced with a new version (GLT-S) developed primarily to improve processing characteristics. Parker Seals has qualified a new compound (VM835-75) based on Viton ${ }^{\circledR}$ GLT-S and the new compound has been approved for transportation. However, the life prediction model in this report only applies to the V0835-75 compound. Additional efforts are under way to develop a comparable model for GLT-S O-rings.

The most important function of an elastomeric seal is that the material maintains an acceptable seal for the intended service and duration. Historically, compression set has been widely used to evaluate seal performance.

Compression set is a measure of the permanent set in an elastomer based on dimension before and after compression for a defined period of time. [11] Compression set is a relatively simple measure that allows comparison between materials exposed to similar conditions. However, compression set behavior depends on many variables. Compression set values can vary with the percent and duration of compression, temperature and recovery time. Unless compared at exact conditions, absolute values of compression set are less meaningful.

After removing the O-ring from the seal gland, compression set is determined. Therefore, the measured value does not truly represent the compression set while in service. However, measurements are typically taken within 30 minutes post-compression to provide a close correlation to the time in service. Compression set is determined per ASTM D395, using a 25\% compression unless otherwise specified [12, 13]. Compression set is usually stated as percentage of original thickness or percentage of deflection, with percentage of deflection more common.

In recent years, compression stress-relaxation (CSR) has become more widely accepted as a better measure of seal performance [14-17]. When an elastomer is compressed, the internal cross-linked polymer structure imposes a spring-like counterforce on mating surfaces to provide a seal. Over time, the sealing force is reduced due to physical and chemical relaxation processes. At some point, the seal may relax enough to allow unacceptable leakage. The relationship between sealing force and leakage is complex and very design specific. Leak rate depends on many variables including differential pressure, temperature, and design parameters such as surface finish, percent compression, gland fill, use of lubricant, and other factors.

CSR is typically expressed as a force decay ratio $\left(\mathrm{F} / \mathrm{F}_{\mathrm{o}}\right)$ or as a percent retained (or lost). The true failure point for an elastomer depends on the application. In studies on critical seals in nuclear weapon components, sealing force ratio of $\mathrm{F} / \mathrm{F}_{\mathrm{o}}=0.10(90 \%$ loss $)$ has been used to define the mechanical lifetime of an elastomer. Though somewhat arbitrary, this value provides some residual counterforce to accommodate reasonable thermal or mechanical changes. More stringent criteria (e.g. 50-75\% loss) may be used, depending on the design and historical performance. Higher values ( $>90 \%$ loss) may also be tolerable but are less conservative. For a highly static seal, practically all sealing force may be lost before leakage occurs. This is evident in gasket materials such as copper, 
Teflon, or flexible graphite that function without measureable counterforce. However, a completely relaxed seal may not respond favorably to changes in the service environment.

\subsection{Baseline Compression Stress Relaxation}

Baseline CSR tests were performed on the Model 9975 O-ring compound per ASTM D6147 at temperatures of $200-400{ }^{\circ} \mathrm{F}$ using the continuous method (Elastocon ${ }^{\circledR}$ ). The $200^{\circ} \mathrm{F}$ temperature roughly matches the maximum O-ring temperature expected in a loss of ventilation scenario. $400{ }^{\circ} \mathrm{F}$ is the "continuous" service limit for the compound and the peak temperature expected during a short-term fire scenario in KAMS. This method offers the advantage of measuring the counterforce very frequently at elevated temperature. The method is less practical for long test periods due to frequent measurement and acquisition of counterforce measurements.

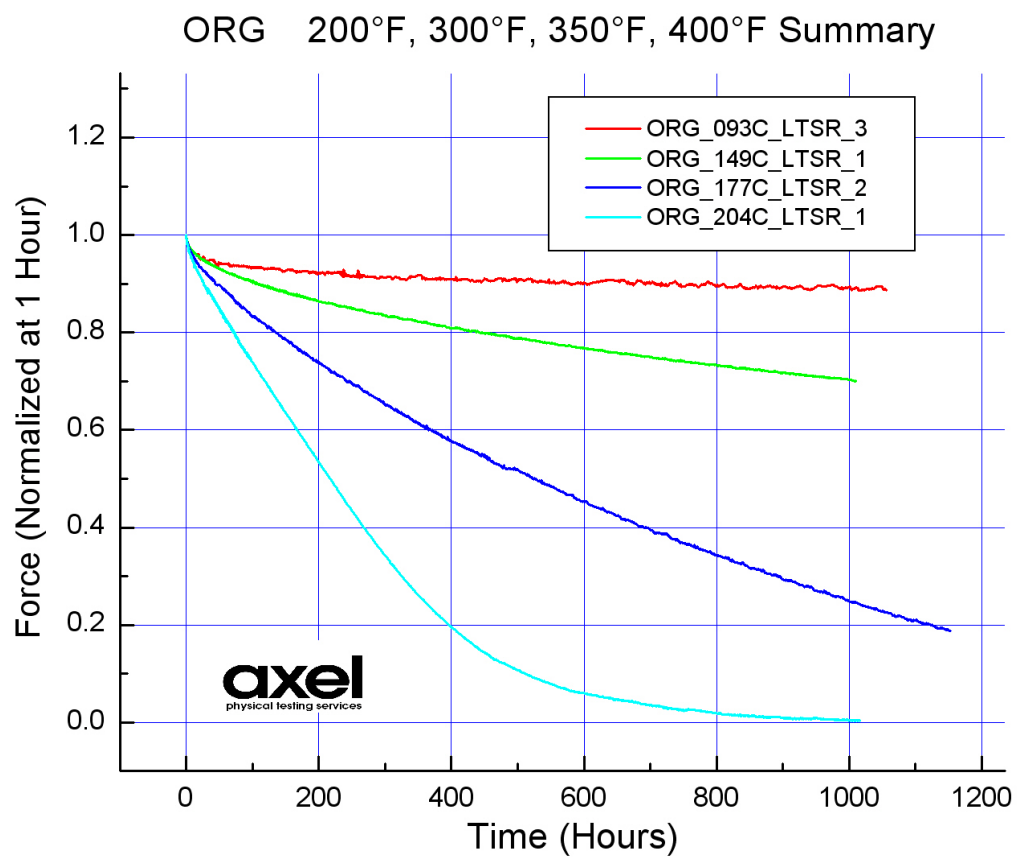

Figure 3 Baseline CSR data for Parker V0835-75 O-rings (size 2-226) vs. temperature.

O-rings of the same thickness (0.139") were used but a smaller size (2-226) was needed to fit in the Elastocon ${ }^{\circledR}$ jigs. The O-rings were compressed to $25 \%$, no ID stretch, and no radial constraint. Baseline results are shown in Figure 3. At $400{ }^{\circ} \mathrm{F}$, the O-rings lost approximately $90 \%$ of sealing force at $\sim 500$ hours and practically all sealing force at $\sim 1000$ hours. This is consistent with the Parker Seals "continuous" temperature limit of $400{ }^{\circ} \mathrm{F}$, which is nominally based on a 1000 hour exposure [4]. Note that even in the highly relaxed state, the elastomer is still pliable and has not degraded in terms of cracking or embrittlement. However, the O-ring shape is permanently deformed and sealing force is lost. The short-term baseline CSR data were used to construct a 
preliminary Arrhenius aging model. Long term performance, however, is used for the current aging model.

\subsection{Long-Term Compression Stress Relaxation}

To refine the baseline model, long-term CSR behavior is being measured per ASTM D6147 using Shawbury-Wallace C11 jigs and a Wallace Mark IV relaxometer (Figures 45). Size 2-213 O-rings (same 0.139" thickness) were needed to fit within the CSR jigs. To mimic the 9975 O-ring design, the O-rings are being tested with a nominal ID stretch of $20 \%$ and a nominal $18 \%$ compression imposed during aging. A $0.0001-0.0002 "$ gap must remain between metal platens on the CSR jig to allow for counterforce measurement.

These tests are being performed in accordance with Task Technical Plan WSRC-TR2007-00276. ASTM D6147 states that a minimum of four aging temperatures should be used for accelerated-aging studies. The aging parameter should be the most relevant for the application. The lowest test temperature should produce the desired property change within one year and should be $15-25{ }^{\circ} \mathrm{C}$ above the maximum service temperature. These are guidelines as the time to reach actual target degradation levels is typically unknown prior to testing.

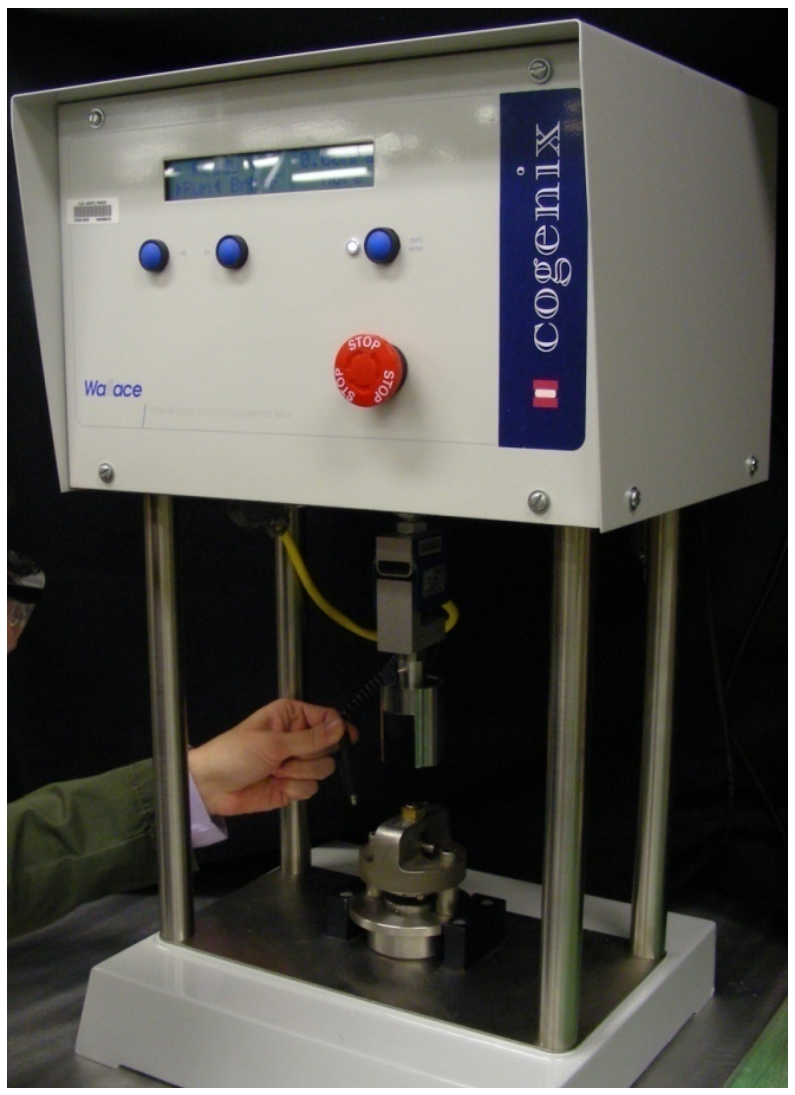

Figure 4 Wallace-Cogenix Mark IV Stress Relaxometer. 


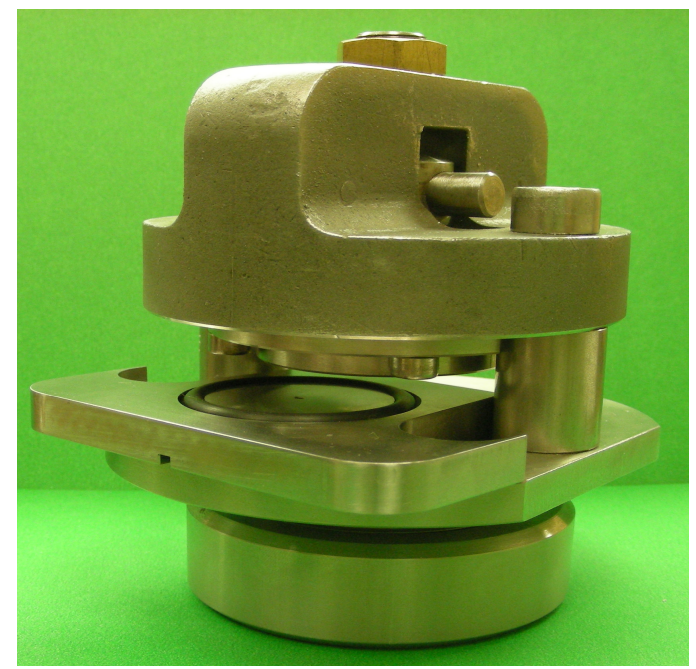

Figure 5 C11 CSR jig with custom 9975 stretch insert.

A concern with accelerated aging is that overly high aging temperatures may result in different degradation mechanisms than those that occur in service. Also, aging at or near known transition temperatures must be avoided since degradation rates may change significantly. In addition, many lifetime prediction studies have shown that diffusionlimited (heterogeneous) oxidation can influence the properties measured. Therefore, aging temperatures and sample configuration must be carefully selected. The material should be tested in the configuration to be used in service as closely as possible.

The aging temperatures selected for the long-term CSR tests were: $175^{\circ} \mathrm{F}, 235^{\circ} \mathrm{F}, 250^{\circ} \mathrm{F}$, $300^{\circ} \mathrm{F}$, and $350{ }^{\circ} \mathrm{F}$. The $175^{\circ} \mathrm{F}$ value represents the peak O-ring temperature anticipated for $104^{\circ} \mathrm{F}$ ambient, the maximum recorded in KAMS. The $235^{\circ} \mathrm{F}\left(113{ }^{\circ} \mathrm{C}\right)$ temperature is $\sim 20^{\circ} \mathrm{C}$ higher than the maximum seal temperature $\left(202^{\circ} \mathrm{F}, 94^{\circ} \mathrm{C}\right)$ expected for a $19 \mathrm{~W}$ package at $130{ }^{\circ} \mathrm{F}$ ambient. $300^{\circ} \mathrm{F}$ is the design limit for the containment vessels. $350{ }^{\circ} \mathrm{F}$ is higher than expected in KAMS during normal service but is less than the "continuous" service rating of $400{ }^{\circ} \mathrm{F}$. Loss of sealing force at $400{ }^{\circ} \mathrm{F}$ was established during baseline tests.

In addition to thermal effects, the possible effects of radiation on CSR behavior were considered. Therefore, some O-rings were irradiated to a 50-year dose $(0.88 \mathrm{Mrad})$ at high dose rates $(0.44 \mathrm{Mrad} / \mathrm{hr}$ for 2 hours) prior to thermal aging. A 50-year dose was imposed to better represent longer storage periods and to see if higher radiation dose has a measurable effect on sealing force decay. This exposure is not intended to duplicate 50 years of aging, as dose rate effects are possible. However, such effects are not expected to be significant at the low doses anticipated.

As the 9975 O-rings are stretched more than recommended by the seal manufacturer, the effect of ID stretch on CSR behavior was addressed by using a custom insert to provide the same nominal stretch and compression as in the 9975 PCV. Test parameters and 
conditions for each jig currently in test are outlined in Table 2. Sealing force measurements are made at isothermal conditions to avoid thermal expansion issues.

Table 2 Testing matrix for compression stress relaxation testing.

\begin{tabular}{|c|c|c|}
\hline $\operatorname{Temp}\left({ }^{\circ} F\right)$ & $\begin{array}{c}\text { Radiation } \\
\text { Dose (Mrad) }\end{array}$ & Stretch Insert \\
\hline 175 & 0.88 & Yes \\
\hline 235 & 0.88 & Yes \\
\hline 250 & 0.88 & Yes \\
\hline 250 & 0 & Yes \\
\hline 250 & 0 & No \\
\hline 300 & 0.88 & Yes \\
\hline 350 & 0.88 & Yes \\
\hline
\end{tabular}

One O-ring was added to a CSR jig without an insert to provide information on nonstretched O-rings. In order for the gap thickness in the loading direction of the nonstretched O-ring to correspond to that of the stretched O-rings, the gap was set to 0.1015 ". This value was determined by adding 0.01 ", the width of the gap, to the gland depth of the insert.

Prior to testing, O-ring hardness was determined (Table 3). The measured values are slightly above the 75+/-5 Durometer Shore A range generally quoted for the V0835-75 compound. This range is for quality control purposes and is a requirement for materials certified to the AMS specification. However, per ASTM D2240 [18], the Durometer A range does not technically apply to O-rings $<0.25$ " thick. Therefore, hardness values obtained in this study were measured using an $\mathrm{M}$ scale O-ring hardness tester, which is a more appropriate method for O-rings of this size per ASTM standards D1414 and D1415 $[11,19]$.

Table 3 M-Scale hardness measurements for as-received Viton ${ }^{\circledR}$ GLT O-rings.

\begin{tabular}{|c|c|c|c|c|c|c|}
\hline $\begin{array}{c}\text { O-ring } \\
\text { ID }\end{array}$ & Test & Test & Test & Test & Test & Average \\
\hline K & 81 & 81 & 81 & 80 & 80 & $\mathbf{8 0 . 5}$ \\
\hline L & 81 & 80 & 80 & 81 & 81 & $\mathbf{8 1}$ \\
\hline M & 80.5 & 80.5 & 80 & 80 & 80 & $\mathbf{8 0 . 2 5}$ \\
\hline N & 81 & 80.5 & 80 & 81 & 79 & $\mathbf{8 0}$ \\
\hline O & 81 & 80 & 80 & 80 & 81 & $\mathbf{8 1}$ \\
\hline P & 81 & 81 & 80.5 & 80 & 81 & $\mathbf{8 1}$ \\
\hline Q & 80.5 & 80 & 81 & 81 & 81 & $\mathbf{8 0 . 7 5}$ \\
\hline R & 81 & 81 & 80 & 80.5 & 81 & $\mathbf{8 1}$ \\
\hline S & 81 & 81 & 80.5 & 80.5 & 80.5 & $\mathbf{8 0 . 7 5}$ \\
\hline T & 80.5 & 80 & 81 & 81 & 80.5 & $\mathbf{8 0 . 5}$ \\
\hline
\end{tabular}

The two scales cannot be directly correlated, though they generally follow similar patterns. These values are consistent with those previously measured during baseline characterization. It is noted that O-ring hardness is not verified prior to installation in the 
9975 packages. The initial hardness for O-rings currently in storage within KAMS is likely consistent with these results due to production controls, though this cannot be verified. Some variation is possible.

CSR jigs with O-rings installed are being aged within Fisher Scientific aging ovens. Ktype thermocouples were attached to each jig using 3M Polyimide Film Tape 5413 Amber Tape to measure the temperature of each jig while in the oven, as well as the temperature change due to heat loss during transfer of the jig from the oven to the CSR apparatus. The jig temperature is not necessarily equal to the O-ring temperature, as the mass of the jig will retain heat compared to the O-ring, and alternatively the thermocouple is mounted to the exterior surface of the jig, while the O-ring is compressed within the body of the jig.

The temperatures of the jigs during CSR testing were lower than the oven aging temperatures. The jigs for the O-rings thermally aged at $175^{\circ} \mathrm{F}$ had the smallest temperature change of $25^{\circ} \mathrm{F}$. The largest temperature change, $50^{\circ} \mathrm{F}$, occurred with the O-ring jigs aged at the highest temperature of $350^{\circ} \mathrm{F}$.

Each CSR force is normalized to a relative CSR force which was also measured at a similar temperature. The relative CSR force, $\mathrm{F}_{0}$, is the measured CSR force at the start of thermal aging, $t_{0}$. The significance in CSR measurements is not the actual force, but the change in the relative force.

Five O-rings were irradiated to $0.88 \mathrm{Mrad}$, and the remaining two are non-irradiated. The two non-irradiated O-rings are used as references for a non-irradiated stretched and nonirradiated, non-stretched O-ring and are being aged at $250^{\circ} \mathrm{F}$. This was selected as a reference temperature due to the limited number of CSR jigs.

CSR measurements are performed five consecutive times for each jig. CSR forces are plotted as a relative force $(\mathrm{F}-\mathrm{B}) /\left(\mathrm{F}_{0}-\mathrm{B}\right)$ over time, where $\mathrm{B}$ is the breakforce at room temperature and $\mathrm{F}_{0}$ is the initial CSR force at time 0 at elevated temperatures, $\mathrm{F}$ is the CSR force taken over the thermal aging period (Figure 6). The relative force rather than actual force is used for comparison purposes due to the unique individual response of each CSR jig.

Fluctuations in relative CSR data for a given aging temperature may stem from variations in testing temperature caused by changes in the time interval between removing the jig from the aging oven and performing the CSR test. Despite variations, a long-term trend can be deciphered for each aging temperature. 


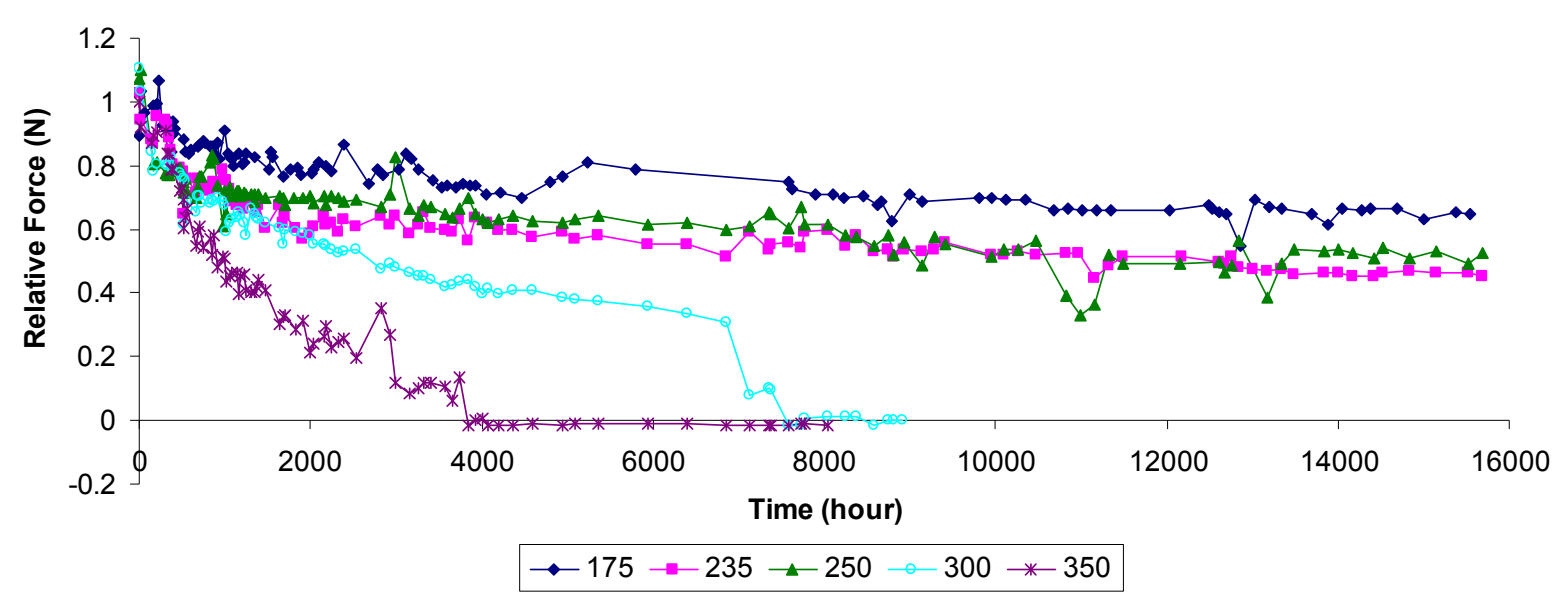

Figure 6 CSR Behavior of V0835-75 O-rings aged at 175 to $350{ }^{\circ} \mathrm{F}$.

From Figure 6, the O-rings aged at $350^{\circ} \mathrm{F}$ lost approximately $90 \%$ of initial sealing force after $\sim 3000$ hours (125 days) and all measurable sealing force at 4000 hours (167 days). Direct comparisons to the baseline data are difficult due to variations in the test equipment, method used and O-ring parameters such as percent squeeze and ID stretch. However, both short-term continuous and long-term CSR testing show a significant reduction in the sealing force at $350{ }^{\circ} \mathrm{F}$ over time. This does not mean that the O-rings are no longer leaktight, only that the counterforce is essentially lost. Mechanically speaking, the O-ring is no longer functioning as an elastomer.

Testing at $350{ }^{\circ} \mathrm{F}$ was stopped due to an aging oven runaway resulting from a power outage. The oven temperature spiked to $450^{\circ} \mathrm{F}$ (oven limit). Fortunately, the samples at $350^{\circ} \mathrm{F}$ had already reached near-zero values of relaxation for life prediction purposes.

CSR values at $300{ }^{\circ} \mathrm{F}$ dropped to near-zero at slightly over 300 days. The reason for the sharper drop at about 270 days is unknown. It is possible that the degree of compression on the $300^{\circ} \mathrm{F}$ jig was inadvertently bumped or adjusted, giving a false drop in sealing force. Once compressed, the jigs can be inadvertently adjusted though they are not delicate. However, the jig is marked or scribed after initial compression and the scribe mark is still aligned.

It is also possible that the elastomer exceeded an inhibition period at $300^{\circ} \mathrm{F}$, with a sharper drop in sealing force due to diffusion-limited oxidation, oxygen consumption or some other mechanism. If so, similar behavior should be observed at some point at the next lower temperature $\left(250^{\circ} \mathrm{F}\right)$, which currently appears to be quite stable. There could also be an unknown variation in the degradation or relaxation mechanism at this particular temperature, or this particular O-ring could have a unique character.

Due to the limited number of CSR jigs available at the time of test start-up, O-rings are currently not being tested in duplicate at all aging temperatures. These tests will continue 
until all measurable sealing force is lost at all lower temperatures or as long as practical. Replicates will be performed to improve the statistical basis.

CSR values at the lower temperatures $\left(175-250^{\circ} \mathrm{F}\right)$ are lower and appear to be stable. In fact, the highest relaxation value reached at all test temperatures within this range thus far is only about $50 \%$ loss, which should be acceptable. This behavior could remain steady for an extended time or values could drop at a faster rate once a threshold aging period is reached. Such a drop has been observed in other elastomers such as EPDM, nitrile and butyl rubber. Such behavior is usually attributed to antioxidant depletion and diffusionlimited oxidation. Being heavily fluorinated ( $64 \mathrm{wt} \%$ fluorine in base polymer), the Viton ${ }^{\circledR}$ GLT-based O-rings are expected to be much more resistant to thermo-oxidation than EPDM and other elastomers, particularly at more realistic service temperatures.

The true long-term stability of Viton-based O-rings can only be confirmed by monitoring and testing at more realistic service conditions for longer periods, though this is not often practical. However, several recent studies have shown that ultrasensitive measurement of the oxygen consumption rate in polymers can be useful in identifying changes in the degradation rate or activation energy at lower temperatures in a more reasonable test period. Ultrasensitive oxygen consumption analyses will be used to identify O-ring degradations.

\subsection{LIFE PREDICTION MODEL}

\subsection{Life Prediction Methodology}

For life prediction at a given service temperature, the time to failure must ideally be known at multiple higher temperatures to allow accurate extrapolation. Arrhenius theory has been used for the life prediction of polymers and elastomers for many years. Other methods have also been used. Svente Augustus Arrhenius (1884-1932) studied the effect of temperature on chemical reactions and biological systems and developed the general rate equation of:

$$
\text { (1) } \mathrm{K}=\mathrm{e}^{-\mathrm{Ea} / \mathrm{RT}}
$$

with $\mathrm{K}=$ reaction rate, $\mathrm{E}_{\mathrm{a}}=$ activation energy, $\mathrm{R}=$ gas constant, $\mathrm{T}=$ absolute temperature (K)

Taking the natural log of the equation gives the form:

$$
\text { (2) } \ln \mathrm{K}=-\mathrm{E}_{\mathrm{a}} / \mathrm{RT}+\mathrm{C}
$$

which follows the equation of a straight line $(y=m x+b)$ with a slope equal to the $-E_{a} / R$ factor and the $\mathrm{X}$-axis $(1 / \mathrm{T})$ has an intercept of the rate constant $(\mathrm{C})$.

If the time to failure is known at several elevated temperatures, an Arrhenius plot can be constructed to predict time to failure at lower temperatures. Key aspects of this method 
are to determine which parameter is most relevant to the application and the failure criterion. Several standards have been developed for Arrhenius-type evaluations.

In the baseline (1000-hour) CSR tests, target relaxation levels (90\%, 100\% loss) were not reached at all temperatures. Therefore, the data at the lower temperatures were linearly extrapolated to produce estimated time to failure values to develop a baseline aging model. The log of time to failure values were then plotted versus the inverse absolute temperature (Figure 7). The temperature scale was converted to Fahrenheit for ease of interpretation and consistency with SARP temperatures.

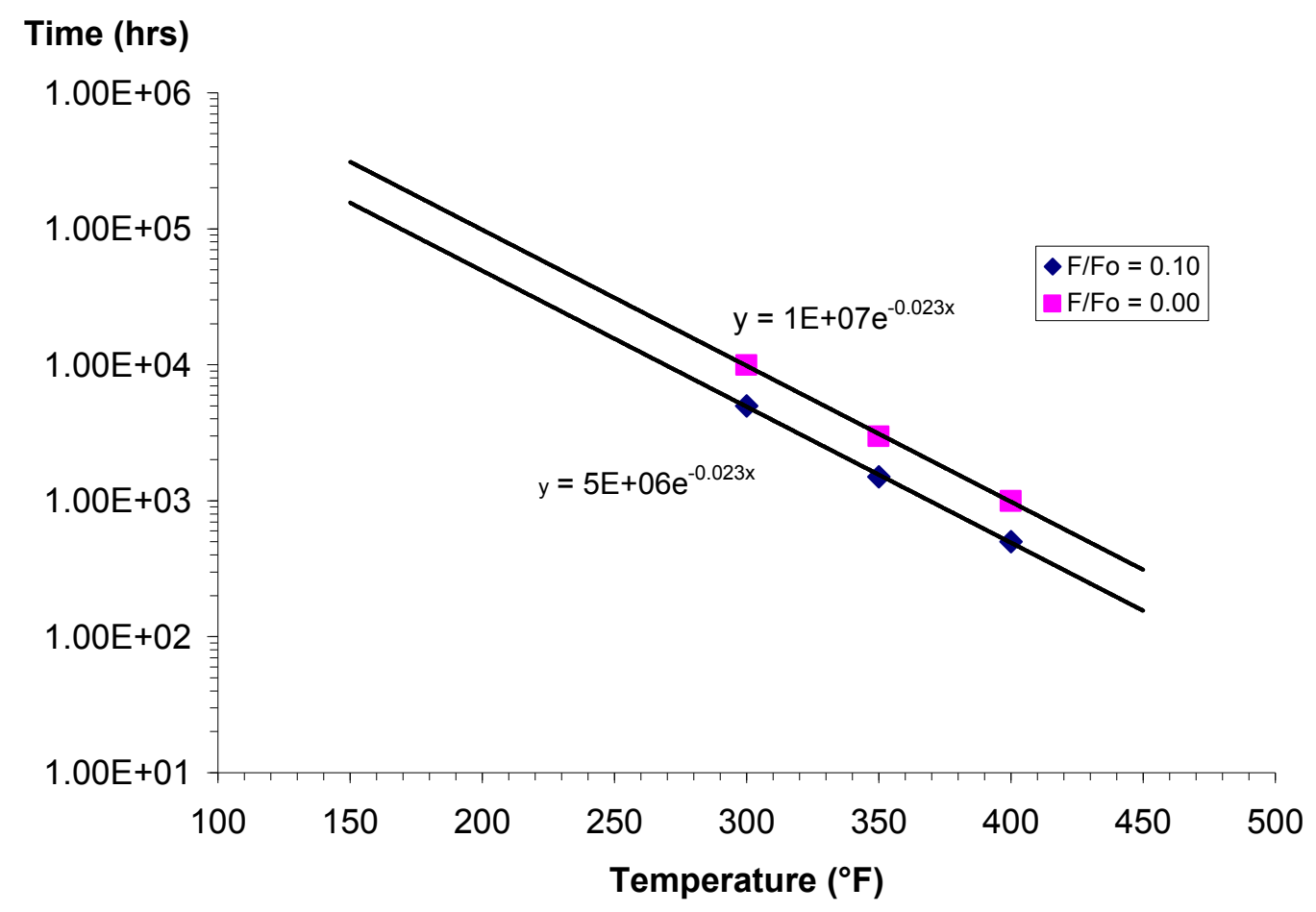

Figure 7 Short-term baseline CSR aging model (time to target relaxation values vs. temperature).

This basic model can be used to predict estimated time to failure at various temperatures, see Table 4. The time to lose $90 \%$ of sealing force is about 2000 hours or 83 days at 350 ${ }^{\circ} \mathrm{F}$. The time to lose $\sim 100 \%$ of sealing force at $350{ }^{\circ} \mathrm{F}$ is estimated at $\sim 3000$ hours or 125 days (4.1 months). At $300^{\circ} \mathrm{F}$, the model predicts time to lose $90 \%$ and $100 \%$ sealing 
force at 0.6 and 1.1 years, respectively. At $250{ }^{\circ} \mathrm{F}$, the model predicts time to lose $90 \%$ sealing force at 1.8 years and time to lose all sealing force at 3.6 years. At $200{ }^{\circ} \mathrm{F}$, the time to lose $90 \%$ and $100 \%$ of sealing force is estimated at 5.7 and 11.4 years, respectively. At $175{ }^{\circ} \mathrm{F}$ (peak PCV O-ring temperature at ambient of $104{ }^{\circ} \mathrm{F}$, the maximum recorded ambient temperature in KAMS), the time to lose $90 \%$ and $100 \%$ of sealing force is estimated at 10.2 and 20.4 years, respectively.

At a more realistic ambient temperature of $85^{\circ} \mathrm{F}$, peak O-ring temperature is reduced to $\sim 158^{\circ} \mathrm{F}$. At $158^{\circ} \mathrm{F}$, the baseline model predicts the time to lose all sealing force at $\sim 28$ years. For packages with lower payload, even longer CSR lifetimes are predicted.

This baseline model has several limitations, some of which are conservative while others are not. First, the model assumes continuous exposure at a single elevated temperature, which is conservative when based on a bounding ambient temperature. Seal temperatures in KAMS will fluctuate with ambient conditions, though such changes will be gradual due to thermal insulation, storage array and facility thermal mass.

Table 4 Estimated time to failure at various temperatures based on the baseline Arrhenius model.

\begin{tabular}{|c|c|c|c|}
\hline $\begin{array}{c}\text { Temperature } \\
\left({ }^{\mathbf{}} \mathbf{F}\right)\end{array}$ & $\begin{array}{c}\text { Loss of Sealing Force } \\
(\mathbf{\%})\end{array}$ & $\begin{array}{c}\text { Estimated Time } \\
\text { (years) }\end{array}$ & $\begin{array}{c}\text { Estimated Time } \\
(\mathbf{h r s})\end{array}$ \\
\hline 175 & 90 & 10.2 & 90,000 \\
\hline 175 & 100 & 20.4 & 179,000 \\
\hline 200 & 90 & 5.7 & 50,000 \\
\hline 200 & 100 & 11.4 & 100,000 \\
\hline 250 & 90 & 1.8 & 16,000 \\
\hline 250 & 100 & 3.6 & 32,000 \\
\hline 300 & 90 & 0.6 & 5,000 \\
\hline 300 & 100 & 1.1 & 10,000 \\
\hline 350 & 90 & 0.2 & 2,000 \\
\hline 350 & 100 & 0.3 & 3,000 \\
\hline
\end{tabular}

The baseline model is also based on linear extrapolation of $\ln (\mathrm{t}) \mathrm{vs} 1 / \mathrm{T}$ to failure values at lower temperatures, which is likely highly conservative. Time to failure will not likely follow a linear trend at all temperatures. A conservative estimate is that the error is likely more significant at lower aging temperatures where short-term relaxation values are minimal.

Another limitation is that the activation energy (degradation mechanism) can sometimes vary for a given material at certain temperatures or over longer periods of time. This can occur for several reasons such as diffusion-limited oxidation (DLO) effects or antioxidant depletion. This is often described as an inhibition period or a "cliff response", where material degradation rates may be relatively slow or stable for an extended period followed by a more drastic change. Life prediction models based on short-term tests at highly elevated temperatures may miss such behavior. Therefore, accelerated-aging tests should be performed for as long as possible and at reasonable temperatures to address 
these factors. If this phenomenon exists in the Viton ${ }^{\circledR}$ GLT O-rings, its effect on the model predictions will be non-conservative.

Other aspects of service in KAMS not addressed in the baseline model are the effect of radial constraint, radiation dose, and ID stretch. The time to lose $100 \%$ sealing force may not always be twice as long as the time to lose $90 \%$ sealing force at all temperatures.

The primary limitation of the Arrhenius method is that it uses only single-point time to failure data rather than all data generated in the experiment. A more comprehensive way to evaluate all of the experimental data is the use of time-temperature superposition principles to determine shift factors to relate all experimental time to failure data to a single plot. This approach is based on the Boltzmann time-temperature superposition principle and the well-known WLF (Williams-Landel-Ferry) equation developed for polymeric materials $[20,21]$.

Therefore, the long-term CSR data set for aging temperatures of $175-350^{\circ} \mathrm{F}$ were used to develop a more refined life prediction model. Rather than only using single time to failure points at each temperature, the time-temperature superposition (TTS) method was used. The primary advantages of this method are: 1) all of the experimental data are used, and 2) the master curve generated for a single reference temperature can be translated to any other temperature of interest using shift factors $\left(\mathrm{a}_{\mathrm{T}}\right)$.

Shift factors are related to temperature as follows:

$\log \mathrm{a}_{\mathrm{T}}=-\mathrm{C}_{1}\left(\mathrm{~T}-\mathrm{T}_{\text {ref }}\right) /\left[\mathrm{C}_{2}+\left(\mathrm{T}-\mathrm{T}_{\mathrm{ref}}\right)\right]=\mathrm{E}_{\mathrm{a}} /\left(\mathrm{R}\left(\mathrm{T}-\mathrm{T}_{\mathrm{ref}}\right)\right)$

where $\mathrm{a}_{\mathrm{T}}$ is the shift factor for the test temperature $\mathrm{T}, \mathrm{C}_{1}$ and $\mathrm{C}_{2}$ are material dependent constants, $\mathrm{R}$ is the gas constant, $\mathrm{E}_{\mathrm{a}}$ is the degradation activation energy, $\mathrm{T}_{\text {ref }}$ is the reference temperature. $T_{\text {ref }}$ is often chosen as the lowest test temperature as this usually provides the best superposition results and most closely represents the service condition. The shift factors are to be determined empirically from the accelerated CSR data. The master curve for $\mathrm{T}_{\text {ref }}$ of $175^{\circ} \mathrm{F}$ is shown in Figure 8. The CSR data plotted in Figure 6 were replotted against logarithmic time. Additionally, the CSR data sets from a range of aging temperatures were empirically time-shifted relative to the $175^{\circ} \mathrm{F} \mathrm{CSR}$ data set to create a single master curve. 


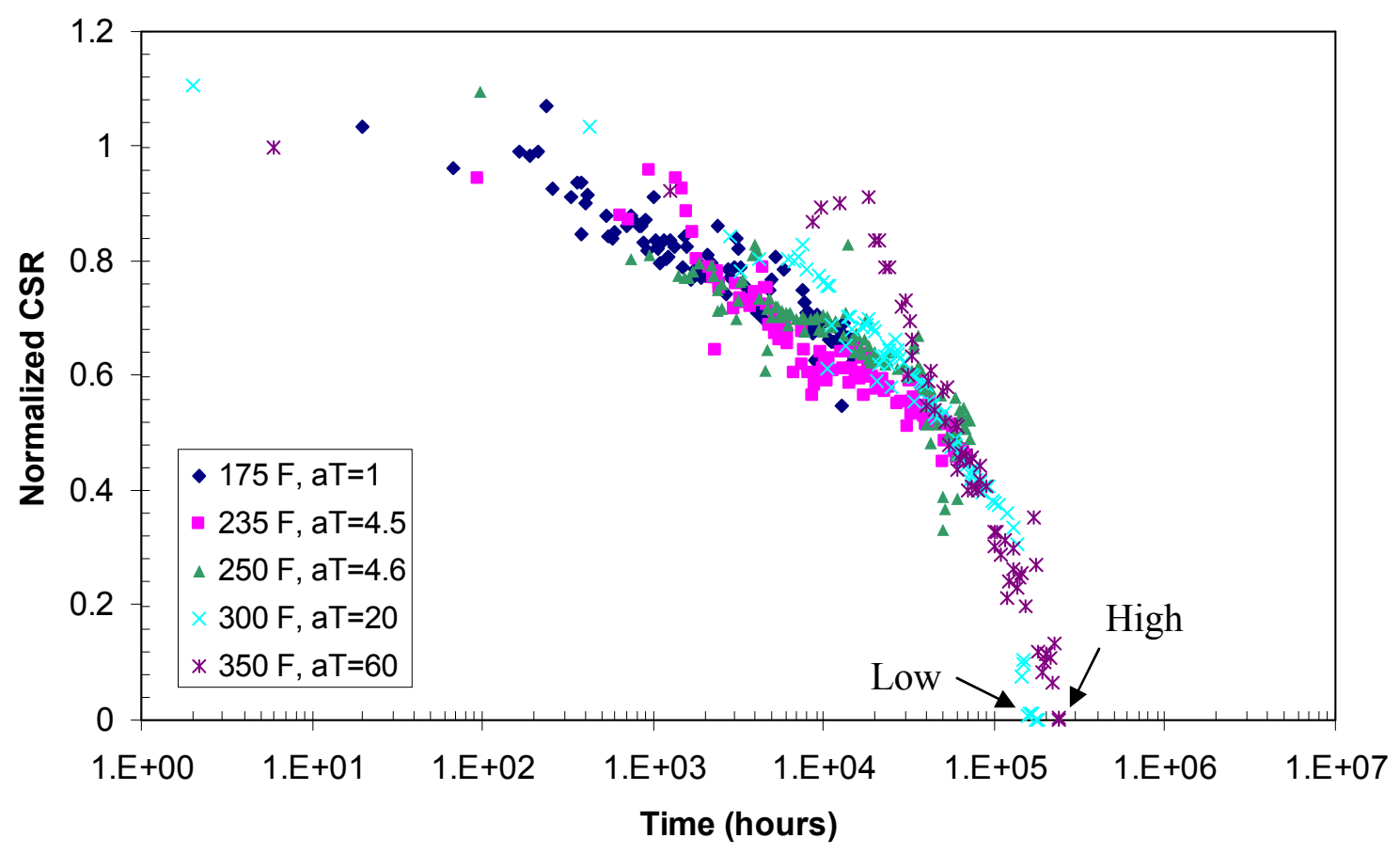

Figure 8 Time-Temperature Superposition curve for V0835-75 CSR data $\left(\mathrm{T}_{\text {ref }}=175{ }^{\circ} \mathrm{F}\right)$. Low and high estimates to $\mathbf{1 0 0} \%$ loss of sealing force are labeled.

All of the accelerated CSR data for each test temperature were empirically shifted using Excel software to find the best curve fit and shift factors. This approach is similar to that used by other researchers for critical seals in nuclear weapon components. The reference temperature chosen for time-temperature superposition of the CSR data was $175^{\circ} \mathrm{F}$, giving a shift factor of 1 at that temperature. Note, the empirically determined shift factors do not follow the expected trend of being proportional to aging temperature. The shift factors were selected based on available CSR data. 


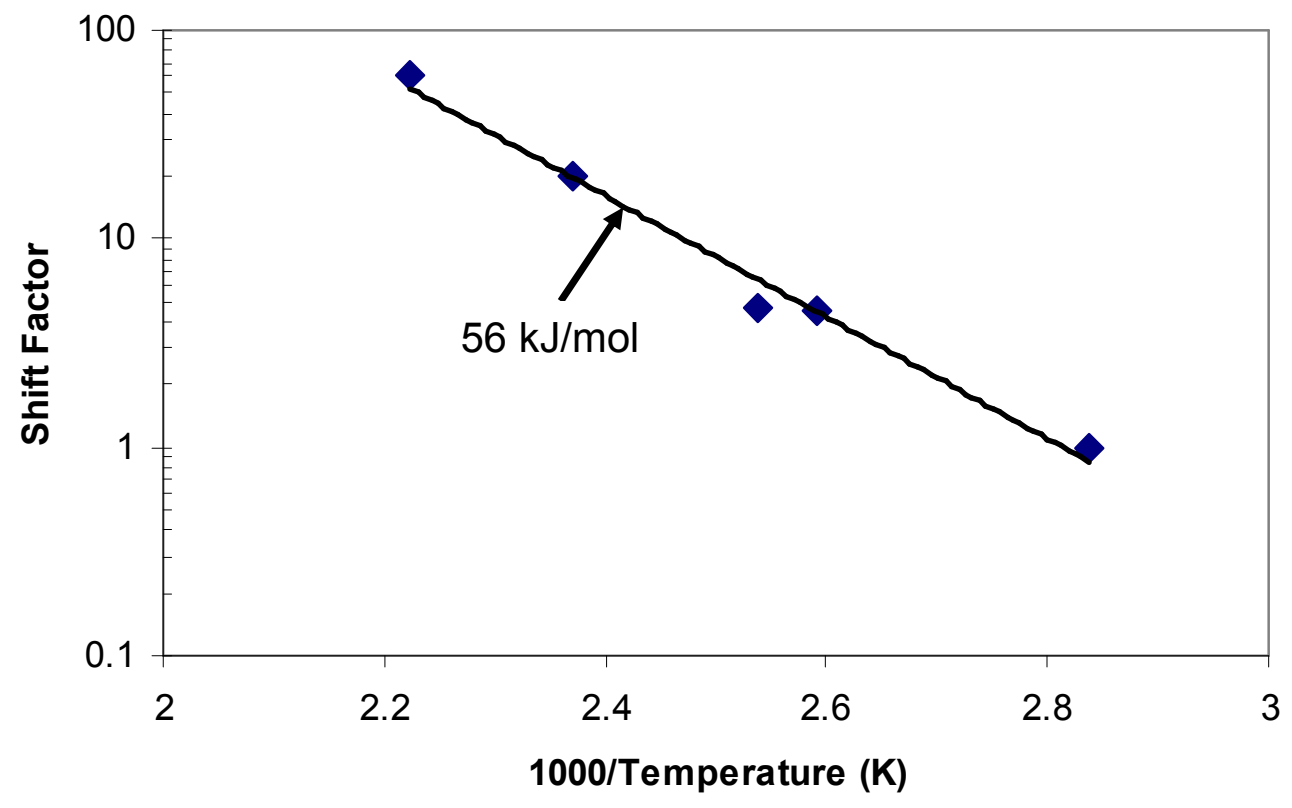

Figure 9 Plot of $\log a_{\mathrm{T}}$ shift factors vs temperature. The activation energy derived from the linear fit is $56 \mathrm{~kJ} / \mathrm{mol}$.

The $\mathrm{a}_{\mathrm{T}}$ shift factors are plotted on a log scale versus inverse absolute temperature in Figure 9, with linear behavior observed. Linear behavior in this plot indicates that the Orings are aging with Arrhenius-type behavior with an $E_{a}$ of $56 \mathrm{~kJ} / \mathrm{mol}$, based on available data. While the existence of two separate slopes is possible due to the potential for two competing degradation reactions, a single line representing a single degradation reaction fits the current data best. The shape or linearity of the plots is quite sensitive to the determination of shift factors. The shift factors associated with the lower thermal aging temperatures currently do not have the confidence level of the shift factors associated with the higher thermal aging temperatures because the CSR data has not dropped to $0 \%$ sealing force at the lower temperatures.

The $\mathrm{E}_{\mathrm{a}}$ of oxidation reactions common in elastomers is typically between $80-120 \mathrm{~kJ} / \mathrm{mol}$ $[14,15]$. When the data are interpreted using a single linear curve fit, then an activation energy of $56 \mathrm{~kJ} / \mathrm{mol}$ is determined. This value is slightly lower than the $80-120 \mathrm{~kJ} / \mathrm{mol}$ range identified for oxidation processes. This may be due to a variation in the degradation mechanism or the limited data set. It is suspected that the relaxation observed at the higher temperatures is primarily related to physical changes in the polymer structure rather than to oxidation processes, which is reasonable given the high resistance of the fluoroelastomer to oxidation. However, only longer tests at lower temperatures in combination with oxygen consumption analysis can validate this assumption.

The master TTS curve in Figure 8 can be time-shifted or translated to other seal temperatures. The first step is to select the temperature of interest and determine the shift factor for that temperature from Figure 9. Then the time scale at the bottom of Figure 8 
can be time-shifted to the target temperature. Alternatively, separate plots can be developed for any temperature of interest.

From Figure 9, the shift factors for several temperatures ranging from $70{ }^{\circ} \mathrm{F}$ to $250{ }^{\circ} \mathrm{F}$ were calculated, Figure 9. The time to failure values from Figure 8 at $175^{\circ} \mathrm{F}$ then were divided by the shift factors, resulting in the determination of the time to failure values at other temperatures not evaluated by CSR testing. Two curves are plotted in Figure 10, using both "low" and "high" estimates of time to failure from Figure 8.

Figure 10 indicates that the O-rings could lose all measurable sealing force after $\sim 178,000$ to 240,000 hours or about 20 to 27 years at $175^{\circ} \mathrm{F}$. An error estimate can be calculated, but the limited number of O-rings will cause it to be large. Using $90 \%$ loss as a conservative failure criterion, Figure 9 indicates only slightly reduced lifetimes due to the relatively sharp drop in normalized sealing force at lower values.

The estimated lifetime plot in Figure 10 gives an overall picture of estimated O-ring service life as a function of seal temperature in KAMS. Seal temperatures are dictated by ambient temperature and payload. Lower ambient temperatures and reduced heat loads will reduce seal temperatures, and ambient temperatures will vary throughout the year. Therefore, seal lifetime will be longer than estimates based on bounding temperatures.

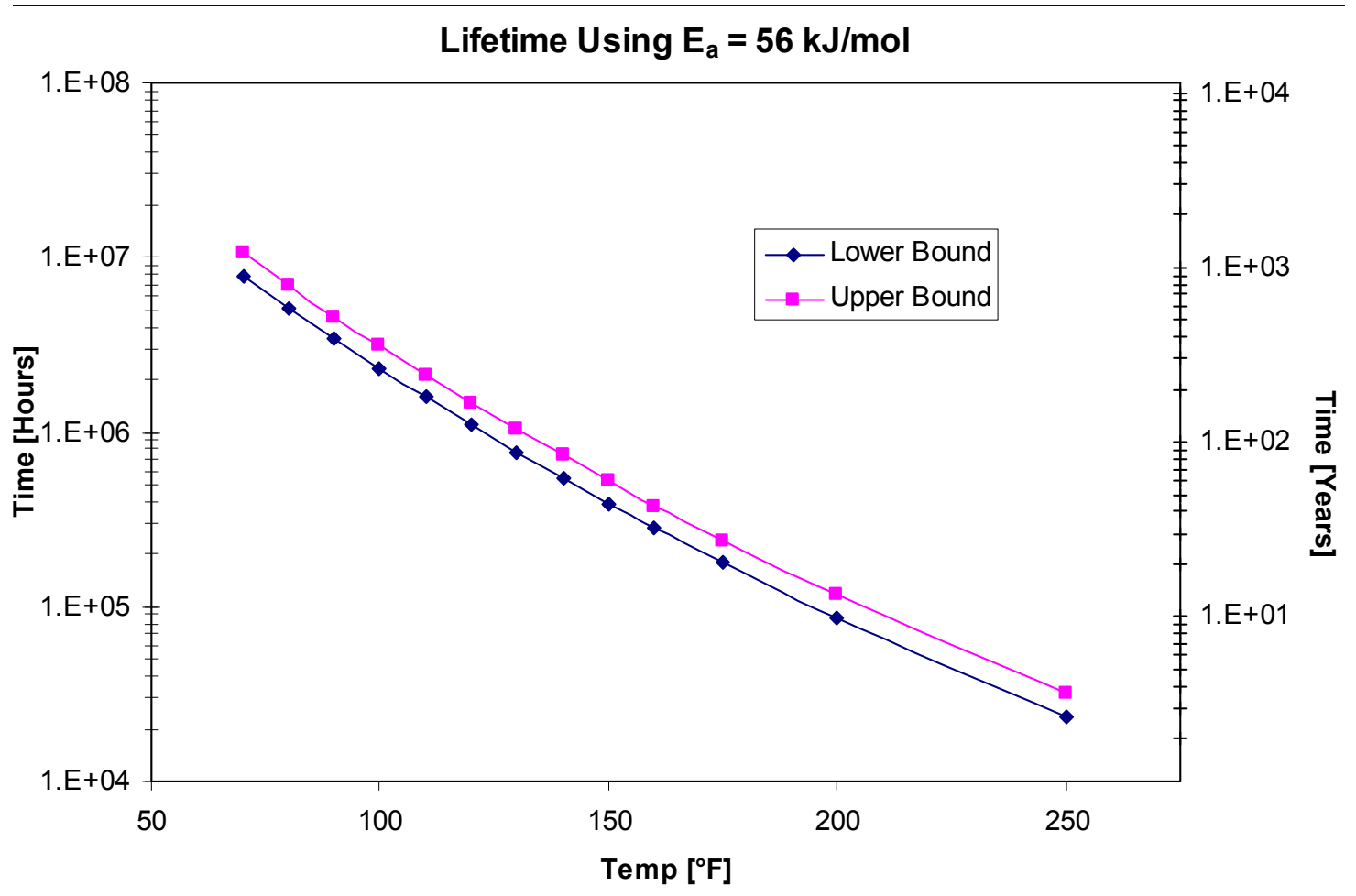

Figure 10 Estimated O-ring service life (based on CSR) vs seal temperature using $E_{a}$ of $56 \mathrm{~kJ} / \mathrm{mol}$. 
Potential deviations in the Viton ${ }^{\circledR}$ GLT lifetime model from the actual GLT lifetime can be attributed to the assumptions built into the TTS model and the limited amount of Viton ${ }^{\circledR}$ GLT CSR data available.

As a comparison, researchers have predicted seal lifetimes of at least 150-200 years for EPDM seals at room temperature, accounting for oxygen consumption rates [16]. The curves in Figure 10 indicate a seal lifetime of 900-1,100 years at room temperature (75 ${ }^{\circ} \mathrm{F}$ ) for the Viton ${ }^{\circledR}$ GLT O-rings, in absence of oxygen consumption data. As there are many variables involved and different failure criterion, it is difficult to make direct comparisons. Oxygen consumption tests may indeed show a reduced service life at lower temperatures than predicted in Figure 10. However, the overall trend is reasonable. Viton ${ }^{\circledR}$ fluoroelastomer is highly fluorinated and much more resistant to oxidation than EPDM and other hydrocarbon elastomers. Therefore a significantly longer service life at similar temperatures is expected.

It is important to note that the model only represents service life in terms of sealing force. Changes in the shift factors can affect the fit of the experimental data and the overall predicted lifetime values. Observations from surveillance examinations and PCV fixture leak tests can be compared to model results. These results are currently being detailed in a separate status report along with surveillance data.

\subsection{Model Limitations and Future Consideration}

Several aspects of O-ring life prediction require additional consideration. The TTS model is dependent on the shift factors $\left(\mathrm{a}_{\mathrm{T}}\right)$ determined, which directly depend on the original data set. Changes in CSR force, particularly in the data set from O-rings aged at the higher temperatures can drastically influence the predicted lifetime. For this reason alone, it is necessary to perform additional testing to ensure repeatability.

Primarily, O-ring service life is strongly dependent on temperature and time at that temperature. The life prediction model presented thus far assumes that the O-rings are constantly exposed at a given temperature. In reality, the seal temperature will vary with ambient condition and payload. Experiments on full size instrumented 9975 packages indicate that the seal temperature requires several days to equilibrate. So seal temperatures will not likely change significantly during any particular day or week. However, the average ambient temperatures during a month or season will change, which can have a significant impact on seal temperatures.

For a more refined life prediction model, cumulative damage accounting for time at less than peak temperatures could be developed. This model would be similar to PalmgrenMiner models developed for cumulative damage (fatigue) in metals and composite materials. Cumulative damage or "wear-out" approaches have been investigated for elastomers. The time to failure at several lower temperatures must ideally be known and the time at such temperatures would have to be known to develop such a model. A preliminary cumulative damage model could possibly be developed from predicted values, but would be less reliable. 
Another aspect to consider is that leakage behavior and sealing force may not be strongly correlated. Sealing force is certainly important, with lower values more likely to allow unacceptable leakage. However, even in a highly relaxed state, the O-ring could remain leaktight if undisturbed. Alternatively, leakage rates could increase at higher values of sealing force, if other design or installation aspects are less than ideal. Additional experiments are planned to better understand this behavior.

Bonding to mating surfaces has been observed at temperatures as low as $300{ }^{\circ} \mathrm{F}$, though more severe at $400-450^{\circ} \mathrm{F}$. Elastomer-to-metal bonding (or via silicone grease oxidation) may enhance sealing beyond the point of zero sealing force, particularly at lower temperatures where thermal changes are less severe. However, the tendency for bonding to occur at lower temperatures is likely reduced. Experiments to evaluate bonding behavior are recommended and planned. Other mechanisms (surface cracking due to embrittlement) are not expected but could occur, possibly leading to O-ring failure sooner than predicted by sealing force. These are not expected but surveillance should continue in order to track behavior. 


\subsection{CONCLUSIONS AND RECOMMENDATIONS}

5.1 Compression stress-relaxation (CSR) data have been used to develop a life prediction model for O-rings made of Parker V0835-75 compound installed in Model 9975 shipping packages used for $\mathrm{Pu}$ storage in KAMS. O-ring service life strongly depends on the seal temperature. Seal temperature is driven by the ambient temperature, package heat load and the storage configuration.

5.2 For model purposes, O-ring lifetime is defined as the time to lose $90 \%$ of measurable sealing force. The preliminary model predicts an O-ring lifetime of approximately $\sim 20-25$ years at a seal temperature of $175^{\circ} \mathrm{F}$, which translates to a maximum payload $(19 \mathrm{~W})$ at a constant ambient temperature of $\sim 104^{\circ} \mathrm{F}$. Lower seal temperatures and reduced payloads will further increase O-ring lifetime. The model predicts a seal lifetime of $\sim 35-45$ years at $158^{\circ} \mathrm{F}$, which correlates to a more realistic 85 ${ }^{\circ} \mathrm{F}$ ambient.

5.3 Leakage rates depend on many design and assembly factors, independent of sealing force. At low sealing force values, these factors become more important. The ability of the seal to respond to environmental or mechanical changes is reduced and possibly non-existent as the relative sealing force value approaches zero. Facility service conditions, including accidents such as dropping or jarring of packages, are not taken into account in the lifetime model.

5.4 The statistical basis for the CSR tests is limited due to the limited number of Orings and fixtures currently in test. Though the O-rings are believed to be very consistent in terms of CSR behavior and other properties due to production controls, additional CSR tests should be performed for statistical purposes.

5.5 All accelerated-aging studies and life prediction models have limitations. To date, target relaxation values have only been observed at temperatures $\geq 300^{\circ} \mathrm{F}$. Values at lower temperatures may not be reached within a reasonable test period. The degradation mechanism and activation energy could also change at lower temperatures, resulting in non-Arrhenius behavior. For service in KAMS, the temperature difference between laboratory aging temperatures and service temperatures is less compared to room temperature and service temperature. The smaller change in temperature between the aging and service temperatures compared to service and room temperature should improve the reliability of the model. This hypothesis can only be determined by longer aging periods or by evaluating additional parameters that are more sensitive to degradation at lower temperatures. Recent studies have shown that oxygen consumption techniques can improve life prediction reliability for elastomeric seals.

5.6 The current aging model only applies to the V0835-75 compound based on Viton ${ }^{\circledR}$ GLT. O-rings made of the VM835-75 compound (Viton GLT-S) are now being used in $9975 \mathrm{~s}$ for shipping and storage in KAMS. Additional experiments to develop a similar model for the GLT-S compound are in process. 


\subsection{ACKNOWLEDGEMENTS}

The contributions of the following individuals to this report are greatly appreciated: Elliot Clark (assistance with time-temperature superposition, DMA testing), Chip Few (data analysis, CSR testing) Dominio' Strom, Connie Yung, Tony Curtis (CSR testing), Larry Feutral/EES (insert design), EES Machine Shop (insert fabrication), Carla Loftin (O-ring hardness testing, leak testing), Bill Cole (Wallace Relaxometer/CSR jig supplier), and AXEL Products (Elastocon CSR testing). Consultation with Robert Bernstein at Sandia National Laboratory and Mark Wilson at Kansas City Plant with regard to CSR testing and data interpretation is much appreciated.

\subsection{REFERENCES}

[1] DOE Standard Stabilization, Packaging, and Storage of Plutonium Bearing Materials, DOE-STD-3013-2004, April 2004.

[2] WSRC-SA-2002-00008, Revision 0, Safety Analysis Report for PackagingModel 9975, December 2003 and S-SARP-G-00003, Revision 0, Safety Analysis Report for Packaging- Model 9975, B(M)F-96, January 2008.

[3] Viton ${ }^{\circledR}$ Fluroelastomer Selection Guide, Dupont Performance Elastomers, Technical Information, Rev. 6 November 2005.

[4] Parker O-Ring Handbook, 2001

[5] Hensel, S., "Steady-State Thermal Analysis of Plutonium Storage in K-Area," Calculation Note, M-CLC-K-00633, Rev. 0, January 19, 1999.

[6] S. M. Herlihy, E. L. Bryant, "KAMS T-1 Temperature Data For Surveillance Staging Determination,” OBU-NMM-2004-00197, October 2004

[7] Radder, J. A. Summary and Matrix 9975 Shipping Package Qualification Program forExtended Storage of Plutonium in the K Area Complex. SRNS-TR-200800290, Rev. 0, Savannah River Nuclear Solutions, Aiken, SC, November 2008.

[8] N-CLC-F-00141, Rev.0, "N-CLC-F-00141, Rev 0, "Shielding Analysis for Plutonium Fluoride Payload in 9975 Shipping Container," September 1998.

[9] WSRC-TR-99-00041 (U), Leak Testing Of Artificially-Aged O-Ring Seals For Model 9975 Packaging Assemblies (U), T.E. Skidmore, February 1999

[10] Hoffman, E.N. SRNL-MST-2006-00110, “Dimensional Calculations for Model 9975 Shipping Package O-Rings (U), December 18, 2006.

[11] ASTM D1414-94 Standard Test Methods for Rubber O-Rings 
[12] ASTM D395-03, Standard Test Methods for Rubber Property-Compression Set

[13] ASTM D 6147 - 97 (Reapproved 2002), Test Method for Vulcanized Rubber and Thermoplastic Elastomer-Determination of Force Decay (Stress Relaxation) in Compression

[14] Gillen, K.T., R. Bernstein, M.H. Wilson. Polymer Degradation and Stability. Vol. 87, 2005: 257-270.

[15] Gillen, K.T., Matthew Celina, and Robert Bernstein. Polymer Degradation and Stability. Vol 82, Issue 1, 2003: 25-35.

[16] K. T. Gillen, M. Celina, R.L. Clough, G.M. Malone, SAND98-1942, New Methods for Predicting Lifetimes in Weapons, Part 1- Ultrasensitive Oxygen Consumption Measurements to Predict the Lifetime of EPDM O-rings, 1998.

[17] "Validation of Improved Methods for Predicting Long-Term Elastomeric Seal Lifetimes from Compression Stress-Relaxation and Oxygen Consumption Techniques”, Polymer Degradation and Stability 82 (2003), K.T. Gillen, M. Celina, R. Bernstein

[18] ASTM D2240, Standard Test Method for Rubber Property - Durometer Hardness

[19] ASTM D1415, Standard Test Method for Rubber Property, International Hardness.

[20] Viscoelastic Properties of Polymers, J.D. Ferry, 3rd Ed, 1980, John Wiley and Sons

[21] Materials Science of Polymer for Engineers, Tim A. Osswald and Georg Menges, Hanser: Cincinnati 1995. 


\section{DISTRIBUTION:}

T.M. Monahon, 705-K

J.W. McClard, 703-H

L.E. Traver, 705-K

E.R. Hackney, 705-K

M.K. Hackney, 705-K

N.C. Iyer, 773-41A

J.S. Bellamy, 773-41A

G.T. Chandler, 773-A

E.N. Hoffman, 773-A

W.L. Daugherty, 773-A

R.L. Bickford, 730-A

T.E. Skidmore, 730-A

K.A. Dunn, 773-41A

G.A. Abramczyk, 773-41A

D.R. LeDuc, 773-41A

P.S. Blanton, 773-41A

A.C. Smith, 773-41A

K.A. Zeigler, 773-41A

T.J. Grim, 105-K

K.P. Burrows, 705-K

J.L. Murphy, 773-41A

J.M. Schuler, DOE_HQ EM-63

A. DiSabatino, LLNL, Blg 1677

Document Control 